\title{
The influence of alkaline cations on the mechanism and kinetics of dehydration of polymeric phthalatocuprate(II) dihydrates
}

\author{
Jelena D. Zdravkovića,*, Dejan D. Poleti ${ }^{\mathrm{b}}$, Jelena R. Rogan ${ }^{\mathrm{b}}$, Vladimir A. Blagojevićc \\ Katalin Mészáros Szécsényi ${ }^{\mathrm{d}}$, Dragica M. Miniće \\ a Innovation Centre - Faculty of Technology and Metallurgy, University of Belgrade, Karnegijeva 4, 11000 Belgrade, Serbia \\ b Department of General and Inorganic Chemistry, Faculty of Technology and Metallurgy, University of Belgrade, Karnegijeva 4, 11000 Belgrade, Serbia \\ ${ }^{c}$ Institute of Technical Sciences SASA, Knez Mihailova 35/IV, 11000 Belgrade, Serbia \\ d Faculty of Sciences, University of Novi Sad, Trg Dositeja Obradovica 3, 21000 Novi Sad, Serbia \\ e Faculty of Physical Chemistry, University of Belgrade, Studentski trg 16, 11000 Belgrade, Serbia
}

\section{A R T I C L E I N F O}

\section{Keywords:}

Heterometallic complexes

Mechanism and kinetics of dehydration

Deconvolution

Phthalate ion

\begin{abstract}
A B S T R A C T
Thermal dehydration of two heterometallic complexes containing dianion of phthalic acid, pht, $\mathrm{Na}_{2}[\mathrm{Cu}$ (pht) $\left.)_{2}\right] \cdot 2 \mathrm{H}_{2} \mathrm{O}, 1$, and $\mathrm{K}_{2}\left[\mathrm{Cu}(\mathrm{pht})_{2}\right] \cdot 2 \mathrm{H}_{2} \mathrm{O}, 2$, was investigated under non-isothermal conditions. Mechanism and kinetics of dehydration were analyzed in detail using TG/DSC/MS measurements, XRPD analysis and FT-IR spectroscopy. The reversibility of dehydration processes was identified. According to XRPD, dehydrated product of 1 maintains original structure, but dehydration of $\mathbf{2}$ undergoes structural transformation giving a dehydrated product of different crystal structure. In both cases dehydration process involves more than one elementary step, which was confirmed using isoconversional methods Deconvolution of this process using Fraiser-Suzuki function yielded two single step processes for 1 and 2. Subsequent kinetic analysis was performed using Màlek algorithm, resulting in the determination of kinetic triplets $\left(E_{a}, A\right.$ and $\left.f(\alpha)\right)$ for each individual step. In addition, the dehydrated complexes were investigated as possible candidates for $\mathrm{H}_{2}$ adsorption, using molecular simulations.
\end{abstract}

\section{Introduction}

For the last decade, design and preparation of transition metal (TM) complexes [1-18] resulted in an extremely wide range of discrete zerodimensional (OD) compounds, and coordination polymers (CPs) with infinite one- (1D), two- (2D) or three-dimensional (3D) frameworks and very diverse structural features. Besides their remarkable architecture, constantly growing interest for these materials is related to their potential application in the fields of separation, heterogeneous catalysis, gas storage, and drug delivery $[1,2]$. Due to their ability to interact with biological systems, antibacterial [4], antifungal [5] and anticancer activity $[6,7]$, copper(II) complexes are of special interest.

Design and synthesis of CPs principally include application of polycarboxylate ligands, which exhibits high affinity toward metal ions and wide variety of coordination modes $[8,9]$. Introduction of a new metal center may contribute to the diversity of structure and topology, influencing the functional properties of the materials, particularly their catalytic, photoluminescent and magnetic properties [15-17].

A special class of CPs are metal-organic frameworks (MOFs), which can be defined as crystalline materials containing a metal atom or metal cluster bonded to organic linkers $[19,20]$. Although not directly stated in this definition, the existence open pores are assumed, because MOFs are often considered as materials for gas storage and separations [21]. In many CPs and MOFs water or some other solvent acts as a ligand or exist as uncoordinated solvent of crystallization. Since it is necessary to eliminate solvents for adsorption application [2], it is desirable to avoid pores collapse upon solvent removal. Therefore, the manner in which the structure changes during desolvation is of high importance.

During our research on TM complexes with anions of phthalic, isophtalic and terephthalic acid [11,18], reversibility of dehydration-rehydration process has been observed at least two times $[14,22]$. Bearing in mind the fact that copper(II)-sodium complex $\mathrm{Na}_{2}\left[\mathrm{Cu}(\mathrm{pht})_{2}\right] \cdot 2 \mathrm{H}_{2} \mathrm{O}$ (pht $=$ dianion of phthalic acid), 1, exhibits complete reversibility during dehydration-rehydration process [22], we also prepared an analogous copper(II)-potassium complex $\mathrm{K}_{2}[\mathrm{Cu}$ (pht $\left.)_{2}\right] \cdot 2 \mathrm{H}_{2} \mathrm{O}, 2$. Contrary to 1 , which structure remains intact upon dehydration, dehydration of $\mathbf{2}$ undergoes structural transformation. Although 1 and 2 cannot be classified as MOFs, but as CPs with 2D and 1D structure, respectively, reversibility of their

\footnotetext{
* Corresponding author.

E-mail address: jtanasijevic@tmf.bg.ac.rs (J.D. Zdravković).
} 
dehydration-rehydration processes lead us to investigate them in more details as a possible candidates for $\mathrm{H}_{2}$ adsorption.

So far, there are only a few detailed studies dealing with thermal behavior of TM complexes [23] during dehydration from the view point of structural changes, while the research related to dehydration of heterometallic complexes is mainly restricted to the structural features [12-17]. The studies concerning thermal stability of heterometallic complexes which incorporate, at the same time, transition and alkali metals, with water molecules bonded to alkaline cations, are even less common. In order to provide deeper insight into dehydration mechanism and kinetics, both compounds were analyzed under non-isothermal conditions in a nitrogen atmosphere.

In addition, considering the influence of water on adsorption properties of CPs along with their attractiveness as gas storage systems $[2,3]$, the sorption properties of anhydrous complexes were examined. Detailed characterization of their structures in conjunction with MD calculations has been performed, and the predicted differences in gas adsorption capability are discussed.

\section{Methods and materials}

Crystal structures of $\mathbf{1}$ and $\mathbf{2}$ were already reported [12], but without experimental details related to the synthesis. For that reason, the complete procedure for their synthesis is presented in the Experimental section. All the reagents were commercially available and used as received without further purification.

\subsection{Synthesis of $\mathbf{1}$ and $\mathbf{2}$}

1: To a solution prepared by vigorous mixing of $\mathrm{NaOH}(0.100 \mathrm{~mol})$ and $\mathrm{H}_{2}$ pht $(0.0500 \mathrm{~mol})$ in $33 \mathrm{~cm}^{3}$ of water, $50 \mathrm{~cm}^{3}$ of $\mathrm{Cu}\left(\mathrm{NO}_{3}\right)_{2}$ $(0.0100 \mathrm{~mol})$ was added drop-wise at room temperature. The instantly formed microcrystalline precipitate was filtered off after being left overnight, washed several times with small portions of $\mathrm{Et}_{2} \mathrm{O}$ and dried at room temperature (yield $88.2 \%$ ). The prepared compound is soluble in water.

2: $\mathrm{H}_{2}$ pht $(0.0250 \mathrm{~mol})$ and $\mathrm{K}_{2} \mathrm{CO}_{3}(0.0250 \mathrm{~mol})$ were dissolved in $100 \mathrm{~cm}^{3}$ of water and reaction is, as expected, accompanied with $\mathrm{CO}_{2}$ evolution. Later, $5 \mathrm{~cm}^{3}$ of $1 \mathrm{~mol} \mathrm{dm}{ }^{-3} \mathrm{Cu}\left(\mathrm{NO}_{3}\right)_{2}$ solution $(0.005 \mathrm{~mol})$ was added drop-wise. After the addition of $\mathrm{Cu}\left(\mathrm{NO}_{3}\right)_{2}$ solution, the mixture was boiled and filtered, giving clear blue solution. This solution was allowed to evaporate slowly at room temperature. After $24 \mathrm{~h}$, the formation of blue rod-like crystals was observed (yield 48.4\%). The prepared compound is soluble in water.

\subsection{Experimental equipment and conditions}

Fourier-transform infrared (FT-IR) spectra were recorded in the transmission mode between 600 and $4000 \mathrm{~cm}^{-1}$ using a BOMEM (Hartmann \& Braun) spectrophotometer with the resolution of $4 \mathrm{~cm}^{-1}$ using $\mathrm{KBr}$ pellets. The X-ray powder diffraction (XRPD) data were obtained on Philips PW-1710 automated diffractometer, using $\mathrm{Cu} \mathrm{Ka}$ radiation, at $40 \mathrm{kV}$ and $30 \mathrm{~mA}$, in Bragg-Brentano geometry. Diffraction data were collected in the range $4^{\circ}<2 \theta<50^{\circ}$ (step scan: $10 \mathrm{~s}$, step width: $0.02^{\circ} 2 \theta$ ) at room temperature. The comparison of experimental and calculated XRPD patterns [12] confirmed the phase purity of the prepared samples.

Thermal data were recorded from room temperature to $1200 \mathrm{~K}$ using TA Instrument Q600 SDT Thermal Analyzer. For non-isothermal degradation kinetics data were collected at 5, 10, 15 and $20 \mathrm{~K} \mathrm{~min}^{-1}$ heating rates. Measuring parameters: sample mass $\sim 8 \mathrm{mg}$, open alumina crucible (sample/reference), nitrogen atmosphere (flow rate $100 \mathrm{~cm}^{3} \mathrm{~min}^{-1}$ ). The calibration of the instrument was conducted for each heating rate. All measurements were repeated at selected heating rates, assuring their reproducibility. Linear baseline was used in the simulation of the thermo-kinetic background.
For TG/MS measurements the thermobalance was coupled online with Hiden HAL RC 301 quadrupole mass spectrometer. Here the sample mass was $\sim 3 \mathrm{mg}$ and the heating rate of $20 \mathrm{~K} \mathrm{~min}^{-1}$. The experiments were carried out in flowing argon gas carrier (flow rate $50 \mathrm{~cm}^{3} \mathrm{~min}^{-1}$ ). Selected ions with $\mathrm{m} / z=1-143$ were monitored in multiple ion detection mode (MID).

\subsection{Dehydration - hydration experiments}

Dehydrated complexes were obtained by heating at $443 \mathrm{~K}$ for $90 \mathrm{~min}$ (1a) and at $423 \mathrm{~K}$ for $60 \mathrm{~min}$ (2a), followed by cooling in a desiccator and weighting. After standing at ambient conditions for $48 \mathrm{~h}$, dehydrated complex 1a absorbs back atmospheric moisture and reverts to $\mathbf{1}$. For a complete rehydration of $\mathbf{2 a}$ it was necessary to keep it under saturated water vapor in a sealed vessel for $4 \mathrm{~h}$. Mass loss during dehydration for 1 was $7.6 \%$ (calc. $7.60 \%$ ), while for 2 it was $7.2 \%$ (calc. $7.12 \%$ ). Mass gains after rehydration were $7.8 \%$ for $\mathbf{1}$ and $6.9 \%$ for 2 .

\subsection{Computational details}

Possible gas adsorption capacity was calculated using molecular dynamics (MD) and Grand Canonical Monte Carlo (GCMC) simulations. MD calculations were used to simulate crystal lattice expansion with introduction of gas molecules and performed using simulated annealing, followed by cell geometry optimization, in a $4 \times 4 \times 4$ supercell with GULP software package [24]. GCMC calculations, performed using Music software [25], were used to calculate gas adsorption isotherms and corresponding binding energies on a fixed crystal lattice in a $4 \times 4 \times 4$ supercell for calculations at $77 \mathrm{~K}$ and $8 \times 8 \times 8$ supercell for calculations at $298 \mathrm{~K}$. All calculations were conducted using Universal Force Field (UFF) [26] with $5 \cdot 10^{6}$ iterations and 0.4 probability for insertion and deletion and 0.1 probability for rotation and translation of the adsorbate molecule, respectively (See Supplement, Figs. S1-S4). Solvent accessible surface area (SASA) was obtained by calculating the Connolly surface for water molecules as a recommended solvent (radius of $1.4 \AA$ ) [27] and then repeating the same process on the resulting surface for a hydrogen molecule (radius of $1.485 \AA$ ) (See Supplement, Fig. S5).

\section{Results and discussion}

\subsection{Thermal behavior of 1 and 2}

Detailed thermal analysis in order to compare the dehydration-rehydration process of $\mathbf{1}$ and $\mathbf{2}$ has been done having in mind previous results concerning $\mathbf{1}$ [22].

Thermal stability and degradation of both complexes were studied by TG/DSC/MS measurements. DSC curves of $\mathbf{1}$ and $\mathbf{2}$ (Fig. 1) up to $1200 \mathrm{~K}$, show that their decompositions occur in multistep processes involving series of endo- and exothermal-steps including dehydration, decarboxylation, oxidation, further fragmentation and probably evaporation of some formed products. The onset temperature for thermal degradation of $\mathbf{1}$ is higher for about $30 \mathrm{~K}$ compared to that of $\mathbf{2}$, emphasizing the difference in their thermal stability.

According to analysis of TG/MS curves, the first mass loss in temperature range, $400-460 \mathrm{~K}$ for 1 and $370-450 \mathrm{~K}$ for 2 , is associated with the release of two water molecules per formula units. This statement is supported by very good agreement between calculated and experimental values (found $7.6 \%$; calc. $7.60 \%$ for 1 and found $7.2 \%$; calc. $7.12 \%$ for 2). The continuous mass loss in 2 shows that the water evaporation practically starts at room temperature (inset in Fig. 1b), while in 1 it begins at higher temperature (TG onset $400 \mathrm{~K}$ ). In both complexes there is only one crystallographically independent $\mathrm{H}_{2} \mathrm{O}$ molecule. In $1, \mathrm{H}_{2} \mathrm{O}$ is very close to the $\mathrm{Na}^{+}$ion (2.29 $\AA$ ), while in 2 , $\mathrm{H}_{2} \mathrm{O}$ is shared between two $\mathrm{K}^{+}$ions with the corresponding distances of 2.62 and $3.19 \AA$. This can explain their different behavior during 

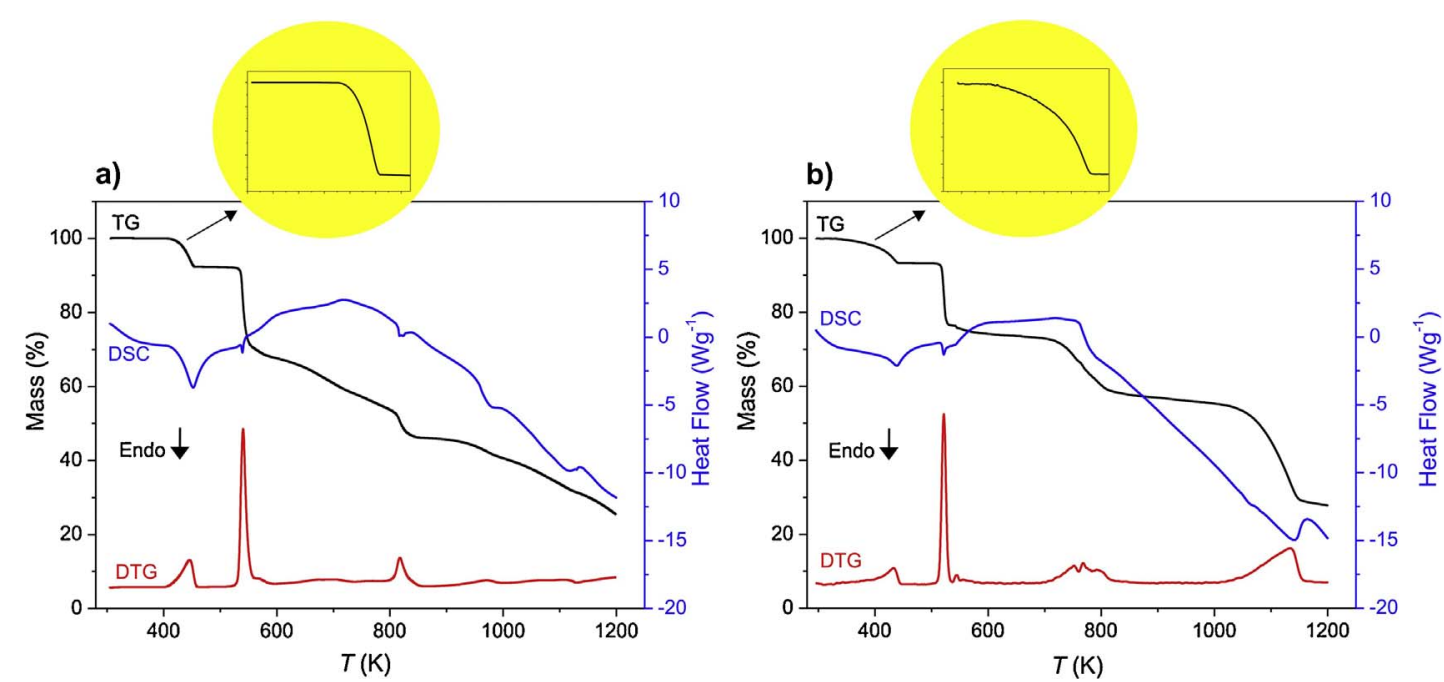

Fig. 1. Simultaneous TG-DSC-DTG plots at $\beta=20 \mathrm{~K} \mathrm{~min}^{-1}$ in an nitrogen atmosphere of: a) 1 b) 2 .

dehydration.

The dehydrated compounds are stable in about $440-500 \mathrm{~K}$ temperature range (Fig. 1). The decomposition starts above $500 \mathrm{~K}$ with $\mathrm{CO}_{2}$ release in both compounds as a consequence of decarboxylation. The signal intensity of $m / z=44$ peak in 2 is about six times higher than in 1. On the contrary, the peak height of $m / z=28$ signal for CO evolution is about ten times higher in $\mathbf{1}$ than in $\mathbf{2}$ (Fig. 2), suggesting that decarboxylation process in 2 mostly consists of $\mathrm{CO}_{2}$ release. In both complexes, $\mathrm{CO}_{2}$ release proceeds practically in the whole temperature range along with $\mathrm{H}_{2} \mathrm{O}$ and $\mathrm{CO}$ evolution due to high hydrogen and oxygen content. Other fragments with a higher $m / z$ ratio $(m / z=50,77,78)$ are also observed around $600 \mathrm{~K}$ but with a significantly lower relative intensity. Fragment with $\mathrm{m} / z=50$ most probably belongs to $\mathrm{C}_{4} \mathrm{H}_{2}{ }^{+}$ion from the benzene ring, while the relative intensity of the fragments with $m / z=77,78$ corresponding to the benzene ring departure, is even lower. In inert atmospheres $\left(\mathrm{N}_{2}, \mathrm{Ar}\right)$ the decomposition is completed around $1200 \mathrm{~K}$. According to the shape of TG curves (Fig. 1), mass loss is continuous above about $930 \mathrm{~K}$ for $\mathbf{1}$, while it is abrupt above about $1070 \mathrm{~K}$ for 2 . This can be correlated to the stability of alkali metal carbonates as very possible intermediates during degradation. In addition to the metallic $\mathrm{Cu}$ in $2, \mathrm{CuO}$ and $\mathrm{Cu}_{2} \mathrm{O}$ are also found in $\mathbf{1}$. No phases indicating the presence of alkali metals were present (See Supplement, Fig. S6). This can be attributed to the appearance of alkali oxides in amorphous phase or to their evaporation in final stages of degradation. Similar results were already obtained for the final decomposition products in inert atmosphere [28].

Thermal analysis showed that the water content loss during dehydration was completely recovered during rehydration (Fig. 3). DSC curves (See Supplement, Fig. S7) of rehydrated complexes have the same shapes as starting materials, indicating process reversibility. Small shift toward lower temperatures (for about $15 \mathrm{~K}$ ) of thermal curves, during dehydration of rehydrated complexes, is a consequence of applied heterogenic rehydration reactions.

\subsection{Structural characterization of 1 and 2}

The difference in thermal behavior of $\mathbf{1}$ and $\mathbf{2}$ upon dehydration-rehydration process can be correlated to their structure. Since crystal structures of $\mathbf{1}$ and $\mathbf{2}$ are known [12], in this section only the main structural features will be presented.

In both complexes, pht ions acts as an overall bridge, with one $\mathrm{COO}$ group coordinated as a chelate and other as a monodentate ligand. Thus, in 2, zigzag polymeric chains are formed by linking through pht bridges. These polymeric chains are oriented along the [101] direction. Unlike 2, which exhibits a chain structure with potassium cations located between the chains, 1 further exhibits a layered structure, where pht also bridges two adjacent $\mathrm{Cu}$ atoms, but due to different orientation of the aromatic rings and conformation of $\mathrm{COO}$ groups, the resulting structure consists of layers parallel to the (100) plane [12]. The only non-molecular interactions among chains in $\mathbf{1}$ are van der Waals forces. In 2 , however, there are additional $\pi-\pi$ stacking interactions between the aromatic rings of pht ions.

The difference in size of sodium and potassium cations has a great impact on crystal structures, and, thus, on their thermal properties. Sodium cations are small enough to intercalate in between the polymeric layers, while potassium cations interpose between chains.

b)

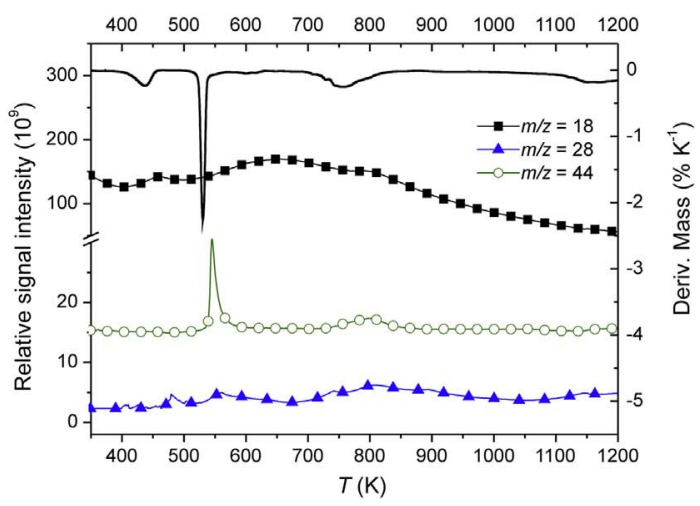

Fig. 2. TG/MS data for dehydration and decarboxylation in argon atmosphere of: a) $\mathbf{1}$ b) 2 . 
a)

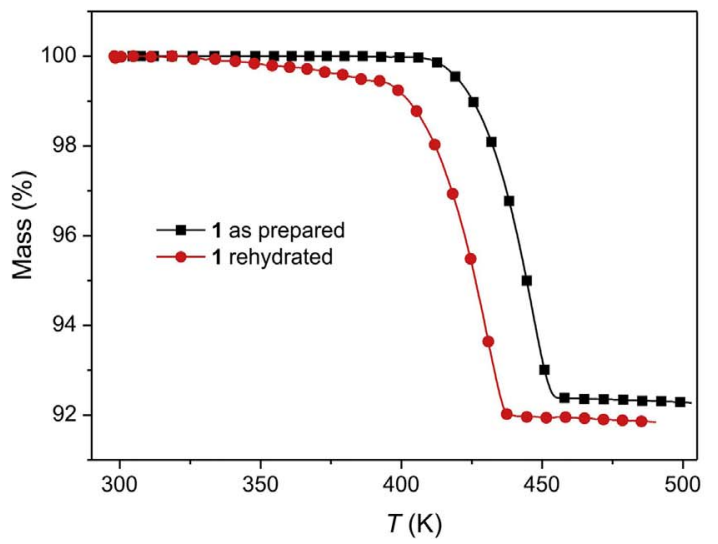

b)

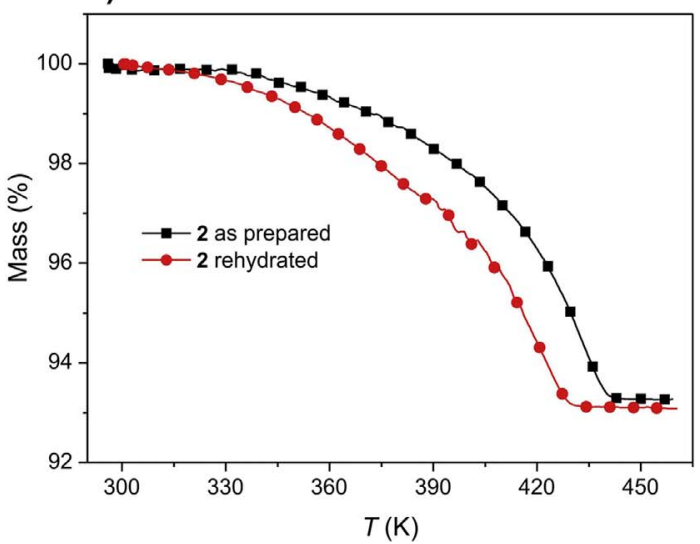

Fig. 3. TG curves of dehydration process of: a) 1 b) 2 (Corresponding DSC curves are presented in Supplement in Fig. S7).

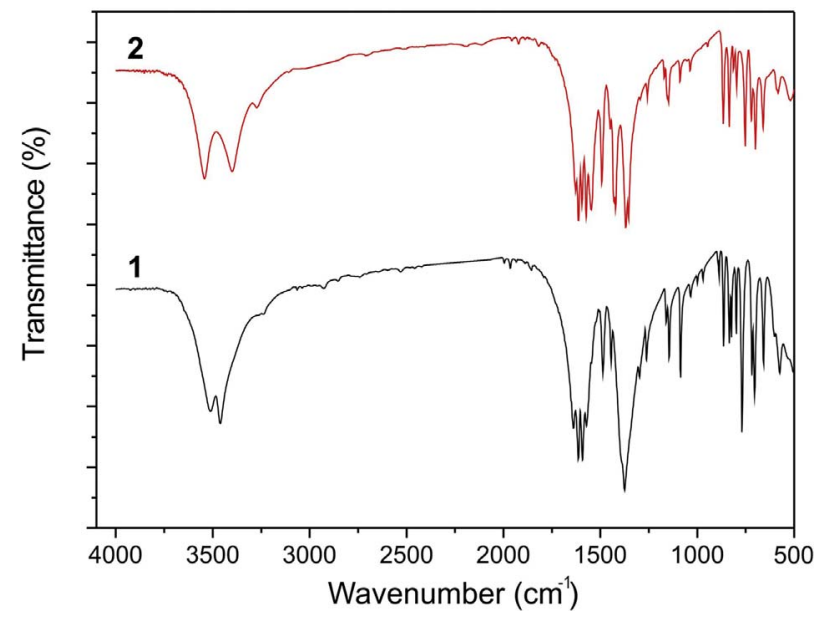

Fig. 4. FT-IR spectra of 1 and 2.

Sodium cation in $\mathbf{1}$ is surrounded by six $\mathrm{O}$ atoms, where five of them belong to pht anions and one is from water molecule, while potassium cation in $\mathbf{2}$ is enclosed with seven $\mathrm{O}$ atoms, five from pht anions and two from water molecules.

FT-IR spectra of $\mathbf{1}$ and 2, are shown in Fig. 4. Two strong, well defined bands at 3510 and $3465 \mathrm{~cm}^{-1}$ in 1,3540 and $3393 \mathrm{~cm}^{-1}$ in 2 are ascribed to the stretching $\mathrm{OH}$ vibrations (Fig. 4). The position of the $\mathrm{OH}$ stretching vibrations in $\mathbf{1}$ indicates similar $\mathrm{O}-\mathrm{H}$ bond lengths and

a)

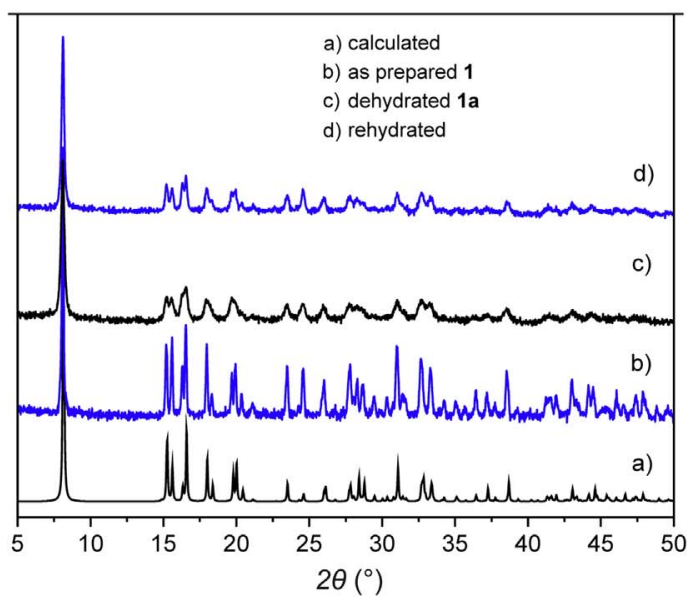

$\mathrm{O}-\mathrm{H} \cdots \mathrm{O}$ distances in hydrogen bonds. The larger separation between positions of the $\mathrm{OH}$ vibrations in 2 comparing to $\mathbf{1}$, is a consequence of their dissimilarity in bond lengths, and thus the strength. As expected, $\mathrm{C}=\mathrm{O}$ and $\mathrm{C}-\mathrm{O}$ stretching vibrations in the spectrum of $\mathrm{H}_{2}$ pht at $1687 \mathrm{~cm}^{-1}$ and $1280 \mathrm{~cm}^{-1}$, respectively [29], appeared as asymmetric $\left(\nu_{\text {as }}\right)$ and symmetric $\left(\nu_{\mathrm{s}}\right) \mathrm{COO}$ bands, in FT-IR spectra of complexes 1 and 2 . The obtained $\Delta \nu\left[=\nu_{\text {as }}(\mathrm{COO})-\nu_{\mathrm{s}}(\mathrm{COO})\right]$ value $\left(218 \mathrm{~cm}^{-1}\right)$ for 1 , and $\left(183 \mathrm{~cm}^{-1}\right)$ for 2 are higher than $\Delta \nu\left(=146 \mathrm{~cm}^{-1}\right)$ for the pure ionic $\mathrm{K}_{2}$ pht salt [30] indicating monodentate coordination [31], because one of $\mathrm{Cu}-\mathrm{O}$ bonds in each chelately coordinated $\mathrm{COO}$ group is very long ( 2.755 for $\mathbf{1}$, and $2.533 \AA$ for 2 ).

Due to their high affinity towards water molecules during the sample preparation, it was not possible to obtain FT-IR spectra of completely dehydrated complexes. However, in the FT-IR spectra of partially dehydrated samples, the changes in $\mathrm{COO}$ coordination modes were not observed.

The complete reversibility of dehydration-rehydration process was also confirmed by XRPD (Fig. 5). For 1, reversibility of dehydration-rehydration process was reported previously [22], where the dehydration-hydration cycles were repeated up to 5 times on the same sample. After standing in air at room temperature for $48 \mathrm{~h}$ dehydrated samples easily absorb the atmospheric moisture. At the same time, no significant changes of unit cell parameters were observed for dehydrated and rehydrated samples (Table 1). However, several new and weak XRPD peaks were detected for anhydrous complex, 2a (Fig. 5b). These could be ascribed to the appearance of a new minor phase or to a decrease in crystallographic symmetry. 2a does not regain its original b)

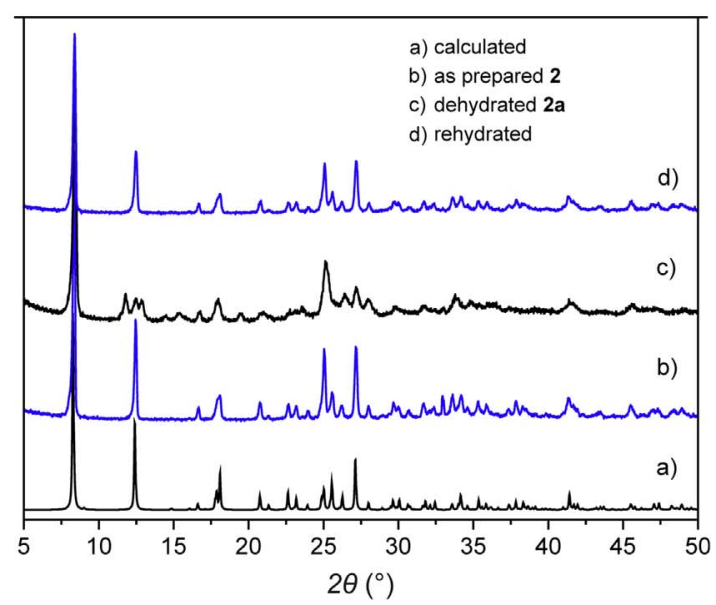

Fig. 5. XRPD patterns of: a) 1 b) 2 . 
Table 1

Unit cell parameters and crystallite size of hydrated and dehydrated complexes.

\begin{tabular}{|c|c|c|c|c|c|c|}
\hline Sample & $a(\AA)$ & $b(\AA)$ & $c(\AA)$ & $\beta\left({ }^{\circ}\right)$ & $V\left(\AA^{3}\right)$ & $<D>(\mathrm{nm})^{\mathrm{a}}$ \\
\hline Single crystal data, 1 & $11.070(10)$ & $6.650(8)$ & $12.143(11)$ & $101.6(1)$ & $875(2)$ & - \\
\hline Powder diffraction data, 1 & $11.079(1)$ & $6.657(6)$ & $12.218(2)$ & $101.7(8)$ & $882(1)$ & $92(9)$ \\
\hline Dehydrated, 1a & $11.142(3)$ & $6.669(1)$ & $12.162(4)$ & $101.6(1)$ & $885(2)$ & $45(2)$ \\
\hline Rehydrated, 1 & $11.091(2)$ & $6.697(1)$ & $12.167(2)$ & $102.1(1)$ & $884(2)$ & $80(9)$ \\
\hline Single crystal data, 2 & $12.065(15)$ & $21.327(16)$ & $7.825(9)$ & $113.9(1)$ & $1841(3)$ & - \\
\hline Powder diffraction data, 2 & $12.063(1)$ & $21.298(2)$ & $7.823(1)$ & $113.6(2)$ & $1842(4)$ & $64(8)$ \\
\hline Dehydrated, 2a & $12.083(3)$ & $21.017(3)$ & $7.773(1)$ & $114.1(4)$ & $1802(4)$ & $32(3)$ \\
\hline Rehydrated, 2 & $12.072(1)$ & $21.278(2)$ & $7.824(5)$ & $113.5(2)$ & $1843(2)$ & $59(9)$ \\
\hline
\end{tabular}

${ }^{\text {a }}$ Calculated by Scherrer's formula.

Table 2

Thermodynamic (for $\beta=20 \mathrm{~K} \mathrm{~min}^{-1}$ ) and overall kinetic parameters $\left(E_{\mathrm{a}}\right.$ and $A$ ) for dehydration process of $\mathbf{1}$ and 2 .

\begin{tabular}{llll}
\hline Complex & & 1 & 2 \\
\hline DSC peak temperature (K) & & 452.1 & 439.1 \\
Formula weight $\left(\mathrm{g} \mathrm{mol}^{-1}\right)$ & & 473.82 & 506.01 \\
Fragment loss & & $2 \mathrm{H}_{2} \mathrm{O}$ & $2 \mathrm{H}_{2} \mathrm{O}$ \\
$\Delta H\left(\mathrm{~kJ} \mathrm{~mol}^{-1}\right)$ & 153.9 & 98.2 \\
$E_{a}\left(\mathrm{~kJ} \mathrm{~mol}^{-1}\right)$ & Kissinger & $95.93 \pm 9.4$ & $82.26 \pm 5.1$ \\
& Ozawa & $98.4 \pm 9.2$ & $84.8 \pm 5.0$ \\
$\ln A\left(\mathrm{~min}^{-1}\right)$ & Kissinger & $26.26 \pm 12.5$ & $22.96 \pm 10.2$ \\
& Ozawa & $27.12 \pm 11.4$ & $23.94 \pm 9.4$ \\
$\Delta S^{\#}\left(\mathrm{~J} \mathrm{~mol}^{-1} \mathrm{~K}^{-1}\right)$ & & -64.1 & -91.3
\end{tabular}

structure (2) by standing in air at room temperature during $48 \mathrm{~h}$, or even after 10 days. Therefore, 2a was exposed to saturated water vapor for $4 \mathrm{~h}$. Under these conditions, 2a quickly regenerated by adsorption of water vapor and regained its original structure (Fig. 5b). Similar behavior was previously observed for some Cu(II) compounds [32,33], where dehydrated complexes reverted to their initial structures by exposing to the saturated water vapor pressure for 12 or $20 \mathrm{~h}$. In some cases it was necessary to put dehydrated sample into water for 6 days to recover its original structure [34].

After removal of water molecules from both complexes, a broadening of the diffraction peaks was observed (Fig. 5), as a consequence of a significant reduction in crystallite size (Table 1). As already stated, the transition from $\mathbf{2}$ to $\mathbf{2 a}$ involves a structural change, yielding a slightly different structure (Fig. 5b). The XRPD pattern of 2a suggests that the dehydrated compound is crystalline in nature and similar to the starting material. Dehydrated products are less crystalline in both cases, whereas the unit cell of $2 \mathrm{a}$ shrinks around $2.2 \%$.

a)

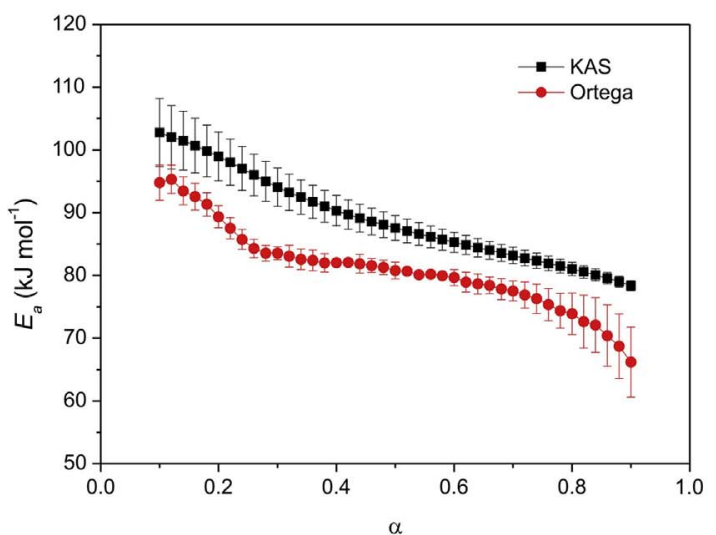

\subsection{Mechanism and kinetics of dehydration}

Dehydration of $\mathbf{1}$ is manifested by the appearance of one compounded asymmetric peak in DTG curves between 400 and $460 \mathrm{~K}$, while for $\mathbf{2}$ it is followed with two highly overlapped peaks in the range of $370-450 \mathrm{~K}$. The kinetics of dehydration was studied based on the shift of well shaped DTG maxima with the heating rate (See Supplement, Fig. S8).

The shift of DTG maxima, indicates the thermally activated process, therefore the overall kinetic parameters for dehydration of $\mathbf{1}$ and $\mathbf{2}$ have been determined using Kissinger and Ozawa equations [35,36] (Table 2), with results that are in close agreement.

High correlation factors from Kissinger and Ozawa methods confirmed that the mechanism of dehydration for both complexes is independent on the heating rate in investigated heating ranges. Therefore, in order to provide deeper insight into the mechanism of dehydration for $\mathbf{1}$ and $\mathbf{2}$, isoconversional methods, the integral Kissinger-Akahira-Sunose (KAS) [35,37] and the differential Ortega [38], were used. These methods are a valuable indicator of process complexity and present a basis for further discussion of the reaction mechanism [39]. The results (Fig. 6) clearly suggest that dehydration for both compounds is a multistep process, involving more than one elementary step [40]. The differences in curves are expected because Ortega method is free of the approximations used in KAS method.

For dehydration of $\mathbf{1}$, the $E_{a, \alpha}$ on $\alpha$ dependences (Fig. 6a) exhibit decreasing, convex/concave character in the whole range of $\alpha$. This can be ascribed to the transition of the limiting step from the breaking of chemical and hydrogen bonds to the diffusion step of released molecules. Initially decreasing convex character of curves is related to the presence of a reversible step during dehydration of 1 [41]. Process complexity for dehydration of $\mathbf{2}$ is particularly obvious from the existence of three maxima in the corresponding curve for Ortega method (Fig. 6b). At the beginning, the increasing nature of both curves

b)

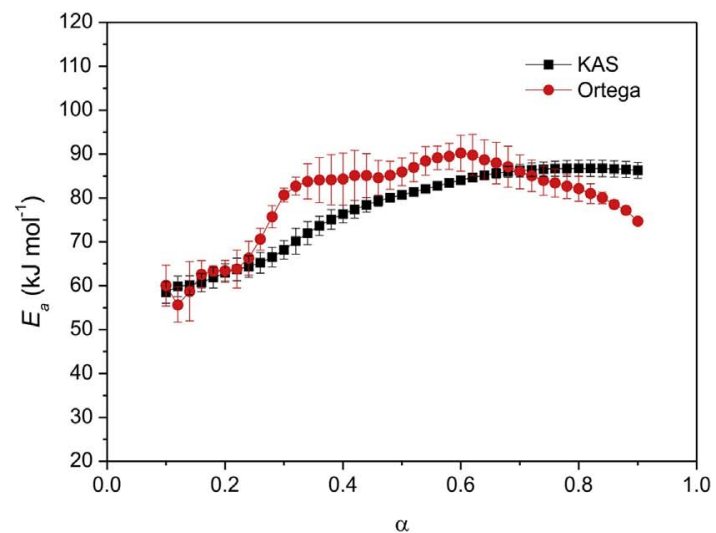

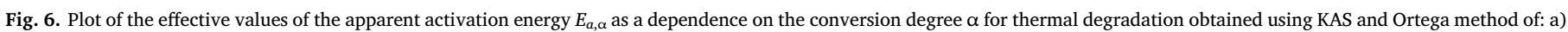
1 b) 2 . 
a)

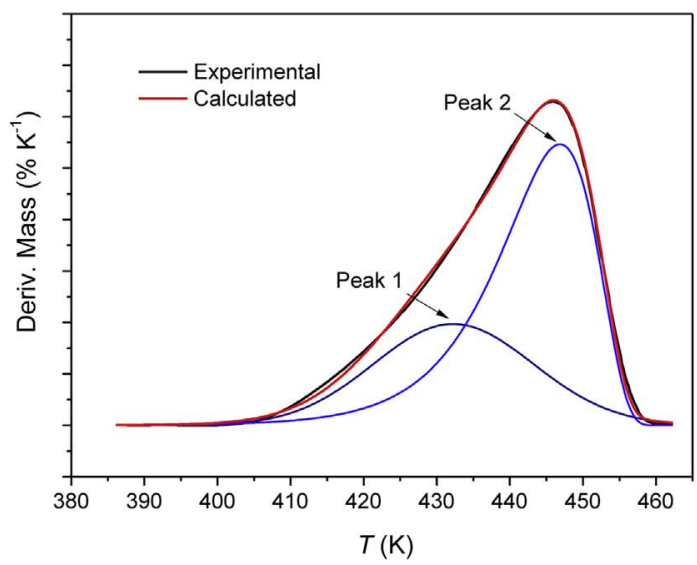

b)

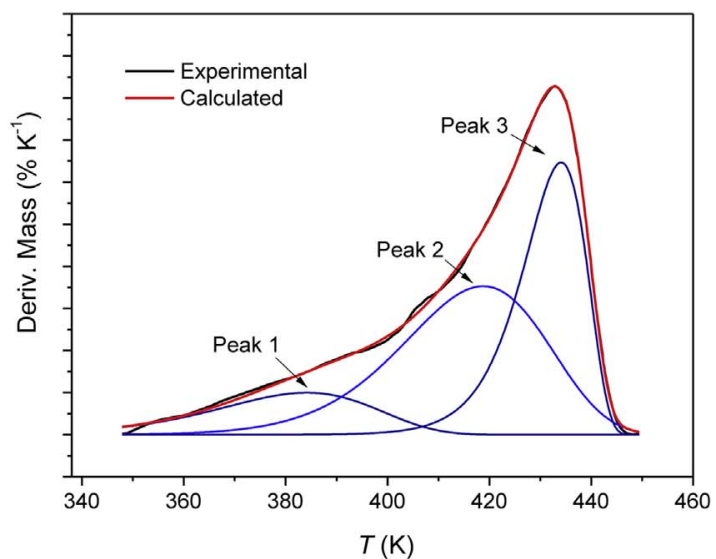

Fig. 7. Deconvolution of complex dehydration process at $\beta=20 \mathrm{Kmin}^{-1}$ : a) for $\mathbf{1}$ b) for 2 .

Table 3

The kinetic parameters of deconvoluted peaks for dehydration of $\mathbf{1}$ and $\mathbf{2}$ determined by Kissinger and Ozawa methods.

\begin{tabular}{|c|c|c|c|c|c|}
\hline \multicolumn{2}{|c|}{ Complex } & \multicolumn{2}{|l|}{ Kissinger } & \multicolumn{2}{|l|}{ Ozawa } \\
\hline & & $E_{a}\left(\mathrm{~kJ} \mathrm{~mol}^{-1}\right)$ & $\ln A\left(\min ^{-1}\right)$ & $E_{a}\left(\mathrm{~kJ} \mathrm{~mol}^{-1}\right)$ & $\ln A\left(\min ^{-1}\right)$ \\
\hline \multirow[t]{2}{*}{1} & Peak 1 & $76.2 \pm 2.8$ & $21.2 \pm 11.1$ & $79.1 \pm 2.2$ & $22.4 \pm 10.8$ \\
\hline & Peak 2 & $88.2 \pm 6.3$ & $24.0 \pm 10.5$ & $90.7 \pm 5.8$ & $24.9 \pm 9.9$ \\
\hline \multirow[t]{2}{*}{2} & Peak 2 & $64.2 \pm 2.1$ & $18.3 \pm 9.6$ & $67.4 \pm 1.9$ & $19.7 \pm 6.6$ \\
\hline & Peak 3 & $79.2 \pm 3.7$ & $22.0 \pm 10.2$ & $81.9 \pm 3.5$ & $23.1 \pm 8.8$ \\
\hline
\end{tabular}
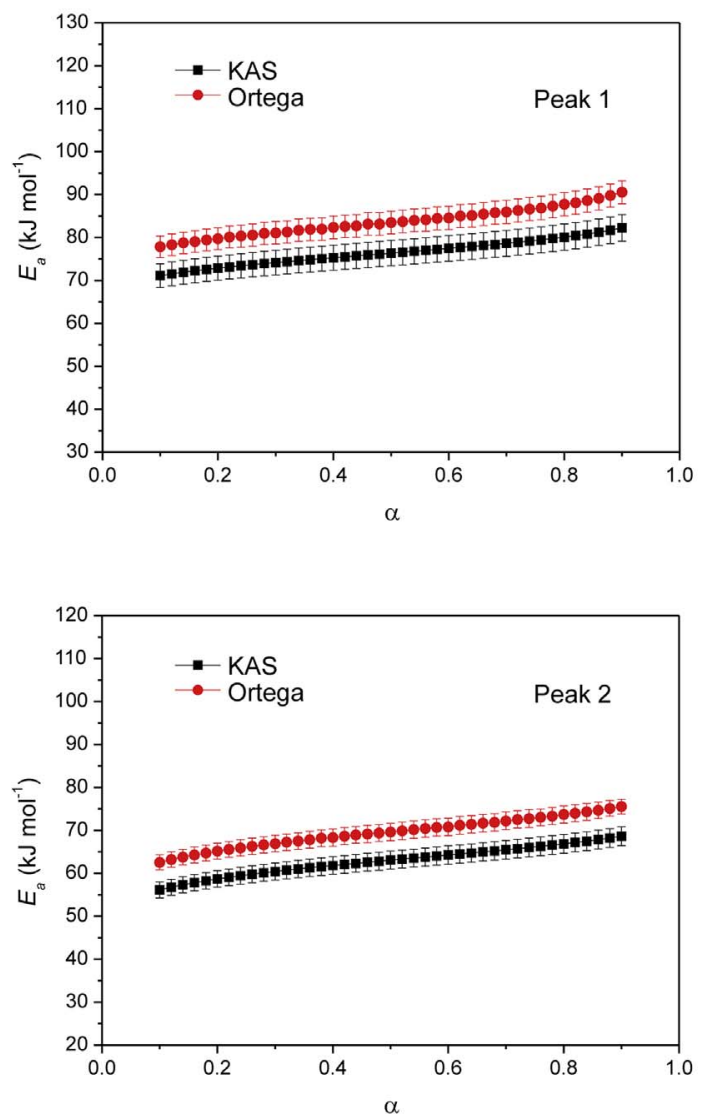

indicates a process that involves parallel reactions, while for $\alpha>0.6$ diffusion becomes predominant, reflecting a transition to a diffusioncontrolled step [41].

Taking into consideration the complex nature of dehydration processes, to gain more information, the peak deconvolution was applied using several mathematical functions recommended for this type of processes [42]. The best results were obtained using asymmetric Fraser-Suzuki function (Fig. 7).

The peaks 1 and 2 for 1 and peaks 2 and 3 for 2 are ascribed to stepwise release of two water molecules from the structure of complexes (Table 3). The presence of continuous mass loss starting at room temperature in $\mathbf{2}$ (Fig. 1b) could be related to the adsorbed moisture

a)

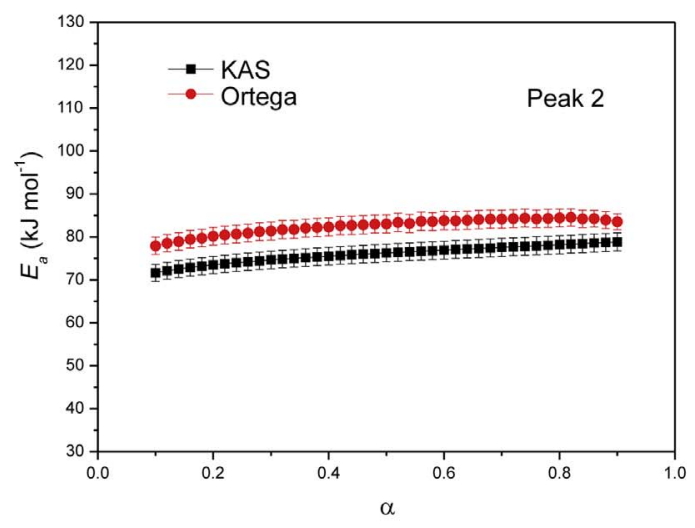

b)

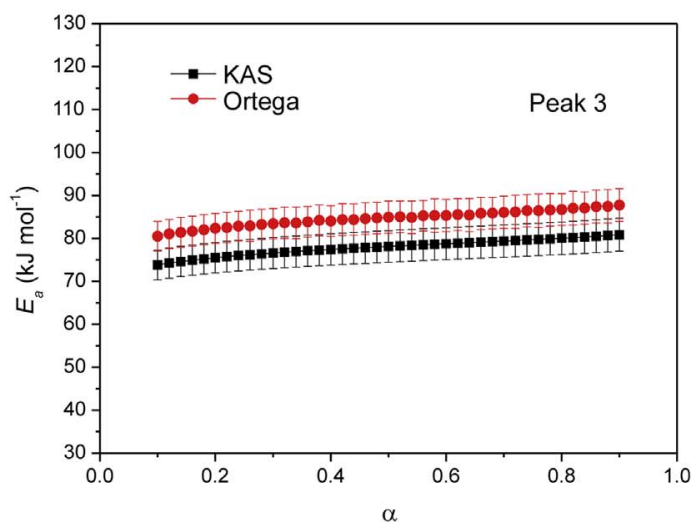

Fig. 8. Values of activation energies at different conversion degree determined using KAS and Ortega isoconversional methods for deconvoluted dehydration peaks of: a) 1 b) 2. 
a)
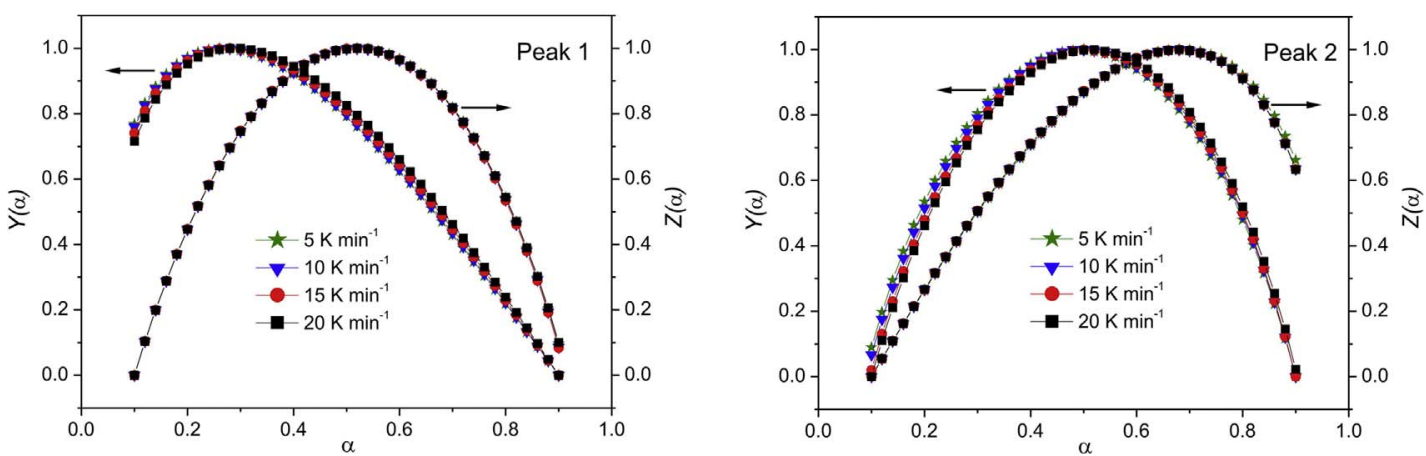

b)
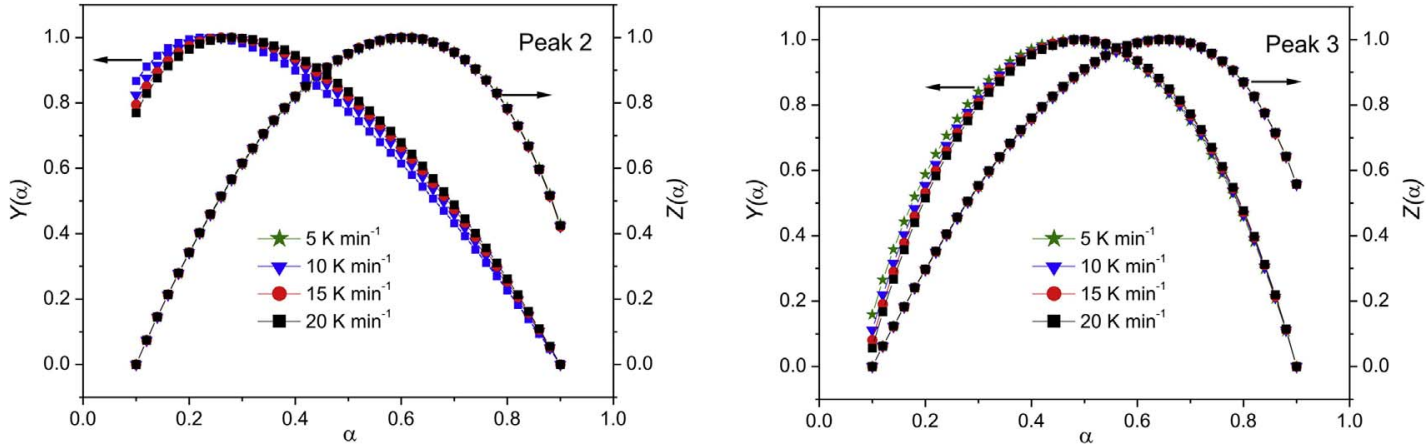

Fig. 9. Màlek curves $y(\alpha)$ and $z(\alpha)$ at different heating rates, determined for dehydration: a) 1 b) 2 .

Table 4

The average position of the maxima of $y(\alpha)$ and $z(\alpha)$ functions and the average values of $\mathrm{M}$ and $\mathrm{N}$ in Šesták-Berrgren model, given for single step processes.

\begin{tabular}{llllll}
\hline Complex & 1 & & & 2 & \\
\cline { 1 - 3 } \cline { 5 - 6 } Dehydration & Peak 1 & Peak 2 & & Peak 2 & Peak 3 \\
\hline$\alpha_{y}{ }^{\max }$ & 0.27 & 0.50 & & 0.27 & 0.48 \\
$\alpha_{z}{ }^{\max }$ & 0.52 & 0.68 & & 0.60 & 0.66 \\
$\mathrm{M}$ & 0.41 & 0.63 & & 0.36 & 0.65 \\
$\mathrm{~N}$ & 1.1 & 0.63 & & 0.97 & 0.71 \\
\hline
\end{tabular}

showed as a long left peak tale in DTG curve, corresponding to peak 1 of 2 (Fig. 7b). It additionally emphasizes its asymmetric shape and was not subjected to kinetic analysis.

The ratio of the areas of separated peaks for 1 is close to 1:1, pointing that equal masses of components leave the system. Deconvoluted peaks of both complexes were analyzed using KAS and Ortega isoconversional methods in order to determine the mechanism of dehydration (Fig. 8).
According to the results of isoconversional methods can be concluded that all deconvoluted peaks correspond to single-step processes (Fig. 8). The closeness of the values of activation energies for the water molecules release, especially in the case of $\mathbf{1}$ is the reason for the existence of one wide endo peak in DSC curves.

Conversion functions for single step processes were determined from the experimental data, according to Màlek algorithm based on the application of characteristic kinetic functions $y(\alpha)$ and $z(\alpha)$ expressed as [43]:

$y(\alpha)=\left(\frac{d \alpha}{d t}\right) \exp \left(\frac{E_{a}}{R T}\right)=A f(\alpha)$

$z(\alpha)=\left(\frac{d \alpha}{d t}\right) T^{2}$

The concave shape of obtained $y(\alpha)$ and $z(\alpha)$ functions suggests the same mechanism of degradation for all applied heating rates, Fig. 9.

Considering the shapes and the positions of maxima of these functions (Table 4), all single steps correspond to the empirically derived Šesták-Berggren model [44] which is expressed as:

Table 5

Simulated lattice expansion data for introducing of $\mathrm{H}_{2}$ into the crystal structures of dehydrated complexes.

\begin{tabular}{|c|c|c|c|c|c|c|}
\hline \multirow[b]{2}{*}{$\begin{array}{l}\text { Amount of } \mathrm{H}_{2} \text {, } \\
\text { (wt.\%) }\end{array}$} & \multicolumn{3}{|l|}{$1 \mathrm{a}$} & \multicolumn{3}{|l|}{$2 a$} \\
\hline & $\begin{array}{l}\text { Relative volume, } \\
(\%)\end{array}$ & $\begin{array}{l}\text { Solvent Accessible Surface } \\
\text { Area, }\left(\mathrm{m}^{2} \mathrm{~g}^{-1}\right)\end{array}$ & $\begin{array}{l}\text { Average binding energy for } \\
\mathrm{H}_{2}\left(\mathrm{~kJ} \mathrm{~mol}^{-1}\right)\end{array}$ & $\begin{array}{l}\text { Relative } \\
\text { volume, (\%) }\end{array}$ & $\begin{array}{l}\text { Solvent Accessible Surface } \\
\text { Area, }\left(\mathrm{m}^{2} \mathrm{~g}^{-1}\right)\end{array}$ & $\begin{array}{l}\text { Average binding energy for } \\
\mathrm{H}_{2}\left(\mathrm{~kJ} \mathrm{~mol}^{-1}\right)\end{array}$ \\
\hline 0 & 100.00 & 0.00 & - & 100.00 & 0.00 & - \\
\hline 0.4 & 103.93 & 0.00 & -10.99 & 101.83 & 0.00 & -8.91 \\
\hline 0.8 & 110.97 & 1.08 & -9.76 & 99.85 & 0.00 & -8.47 \\
\hline 1.2 & 108.51 & 2.08 & -7.74 & 101.39 & 0.00 & -8.82 \\
\hline 2.0 & 114.53 & 26.67 & -8.04 & 102.74 & 0.00 & -6.09 \\
\hline 2.5 & 121.87 & 79.37 & -7.98 & & & \\
\hline 3.2 & 129.62 & 197.73 & -7.29 & & & \\
\hline 4.0 & 142.55 & 868.60 & -6.69 & & & \\
\hline
\end{tabular}


a)

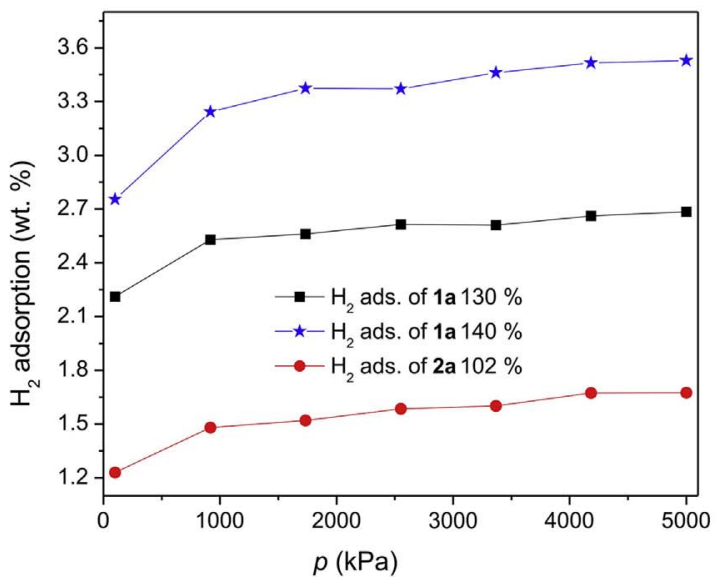

b)

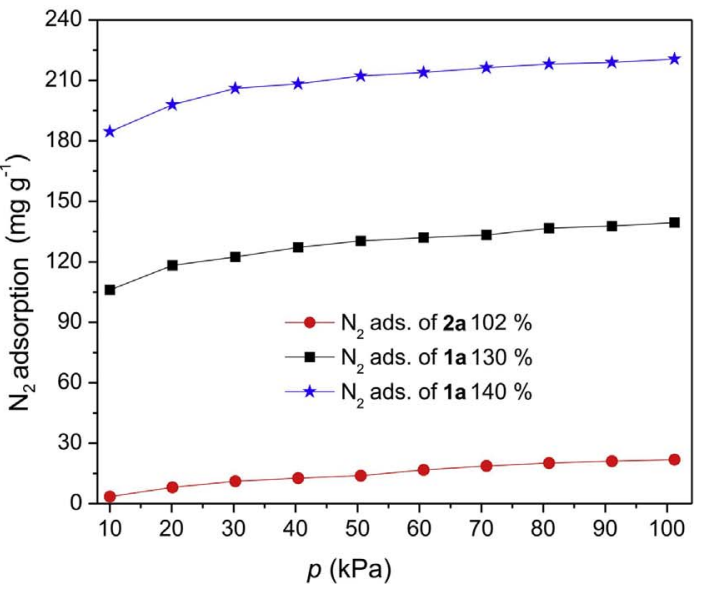

Fig. 10. Calculated adsorption isotherms at $77 \mathrm{~K}$ for: a) $\mathrm{H}_{2}(100-5000 \mathrm{kPa})$ and b) $\mathrm{N}_{2}(10-100 \mathrm{kPa})$.

$f(\alpha)=\alpha^{M}(1-\alpha)^{N}$

where M and N (Table 4) are kinetic parameters (See Supplement, Fig. S9).

The validity of the proposed kinetic triplets $\left(E_{a}, A\right.$ and $\left.f(\alpha)\right)$ for all single step processes of dehydration was confirmed using Master-plot [45] and Pérez-Maqueda [46] criteria. The full accordance between experimental and theoretical master curves (See Supplement, Fig. S10) was observed. The same is true for Pérez-Maqueda criterion as shown by high linearity with correlation coefficients, $R^{2}$ higher than 0.995 , for all individual steps (See Supplement, Fig. S11).

\section{4. theoretical investigation of adsorption properties of dehydrated complexes}

The design of MOF-based materials with high gas storage capacity needs to have a molecular-level understanding of the interactions. Therefore, several investigations dealing with $a b$ inito quantum mechanical studies on the finite structure of MOFs have been performed [47]. The most comprehensive calculation analysis of gas sorption properties for selected coordination compounds from CSD [48] was performed by Goldshmith et al. [19]. These calculations are very useful for predictions of adsorption capacity and subsequently for further tune the chemistry of the framework [49].

In this contribution, gas adsorption for $\mathrm{H}_{2}$ and $\mathrm{N}_{2}$ in both dehydrated complexes was calculated using molecular simulations, and the obtained results are presented in a comparative manner. Various amounts of hydrogen molecules were inserted into both structures using simulated annealing to investigate lattice expansion due to the presence of hydrogen in the lattice. Successive structures were then created by gradually increasing the amount of hydrogen using previously optimized crystal structure as the initial guess. The cut-off value of hydrogen binding energy, beyond which further adsorption was not considered, was $6 \mathrm{~kJ} \mathrm{~mol}^{-1}$.

The results for simulated lattice expansion of both complexes are summarized in Table 5. There is no Solvent Accessible Surface Area (SASA) observed in $\mathbf{2 a}$ at any point, suggesting that this complex would only adsorb gas on the surface of crystalline grains. 1a shows different behavior, where SASA is observed after lattice expansion of around 10 $\%$ and it increases with increase in relative lattice volume. This suggests that 1a could adsorb gas if gas molecules could intercalate between the layers in the crystal structure. In addition, the average binding energies for hydrogen are generally higher in $\mathbf{1 a}$ than in $\mathbf{2 a}$, further reinforcing superiority of 1a for hydrogen adsorption.

Layered structure of 1a allows the introduction of up to $4 \mathrm{wt} . \%$ of $\mathrm{H}_{2}$ into the lattice, resulting in lattice expansion of over $40 \%$. This amount of $\mathrm{H}_{2}$ inserted into 1a is higher than for MOF UiO66 [50] that have similar SASA value. However, $2 \mathbf{a}$ has shown that it was possible to introduce only $2 \mathrm{wt} . \%$ of $\mathrm{H}_{2}$, which results in lattice expansion of less than $3 \%$. The addition of more amount of $\mathrm{H}_{2}$ could not be physically accommodated by the lattice, indicating that the limit of lattice flexibility in 2a has been reached. This shows that there is a huge difference in lattice flexibility between two investigated complexes, allowing 1a to accommodate significantly higher amounts of adsorbed gas. In addition, the average binding energies for hydrogen are generally higher in 1a than in 2a.

The calculated gas adsorption isotherms for 1a and $\mathbf{2 a}$ for $\mathrm{H}_{2}$ and $\mathrm{N}_{2}$ at $77 \mathrm{~K}$ are given in Fig. 10. These results show that 2a could adsorb only around $1.7 \mathrm{wt} . \%$, while $1 \mathrm{a}$ system would adsorb $3.5 \mathrm{wt} . \%$ of $\mathrm{H}_{2}$ at $77 \mathrm{~K}$ and pressures up to $5000 \mathrm{kPa}$.

The difference between 1a and 2a systems is much more pronounced for $\mathrm{N}_{2}$ adsorption, where 1a exhibits up to 15 times higher adsorption. The superiority of $\mathbf{1 a}$ above $\mathbf{2 a}$ is additionally confirmed for adsorption of $\mathrm{CO}_{2}, \mathrm{NO}$ and $\mathrm{CH}_{4}$, at $298 \mathrm{~K}$ (See Supplement, Fig. S3), while calculations of $\mathbf{2 a}$ system showed negligible adsorption of these gasses (See Supplement, Fig. S4).

In summary, these calculations are performed on dehydrated complexes 1a and 2a. As shown in Table 1, no significant structural changes were observed during dehydration-rehydration of 1 . Thus adsorption of $\mathrm{H}_{2}$ and other gases in layered structure of $1 \mathrm{a}$ is quite possible. On the other hand, there is a significant shrinkage of the unit cell along $b$-axis of 2a (Table 1) that additionally promotes the influence of $\pi$ - $\pi$ (see above) stacking interactions between the aromatic rings bringing chains mutually closer. Therefore, adsorption of gases is possible only on the material surface.

\section{Conclusions}

The investigated complexes, due to different crystal structures, show certain differences in their thermal behaviour. The change of co-cation has a great impact on the crystal structure and thus on the thermal properties. The size of co-cation causes the dimensionality of polymeric phthalatocuprates(II). In layered structure of $\mathbf{1}$, the sodium cations are small enough to insert in the hollows of the polymeric layers, while in chained structure of $\mathbf{2}$ the potassium cations interpose between adjacent chains. Both complexes show complete reversibility of dehydration-rehydration process, in spite of structural transformation of $\mathbf{2}$, during dehydration. The lower rate of rehydration of $\mathbf{2}$ could be related to its structural transformation occurring during dehydration.

Thermal degradation process of complexes follows similar pattern involving steps of dehydration, decarboxylation, oxidation, further fragmentation and evaporation of formed products. The dehydration 
processes for both complexes follow the same mechanism, close kinetics but different thermodynamics implying better stability of $\mathbf{1}$. Kinetics similarity is especially evident in their conversion functions presented by Šesták-Berggren model. Higher values of kinetic parameters $\left(E_{a}, \mathrm{M}\right.$ and $\mathrm{N}$ ) as well as higher enthalpy for $\mathbf{1}$ are related to its better thermal stability.

The calculation of gas adsorption for $\mathrm{H}_{2}$ in both dehydrated complexes, 1a and 2a, showed that $1 \mathbf{a}$ is a better candidate with the ability to accommodate up to $4 \mathrm{wt} . \%$ of $\mathrm{H}_{2}$ into the lattice, resulting in lattice expansion of over $40 \%$. This showed that layered structures, although not as rigid as MOFs, could also be good candidates for $\mathrm{H}_{2}$ adsorption. It seems that in our case key for a possible application is the absence of structural changes during dehydration.

\section{Acknowledgements}

The authors are grateful for the assistance of Dr. Predrag Vulić from Department of Crystallography, Faculty of Mining and Geology, University of Belgrade with the XRPD analysis. Support for this work by the Ministry of Education, Science and Technological Development of the Republic of Serbia (Grants No. III45007, 175020) is gratefully acknowledged.

\section{Appendix A. Supplementary data}

Supplementary data associated with this article can be found, in the online version, at http://dx.doi.org/10.1016/j.jaap.2017.05.014.

\section{References}

[1] (a) X.H. Bu, M.L. Tong, H.C. Chang, S. Kitagawa, S.R. Batten, Angew. Chem. Int Ed. Engl. 43 (2004) 192;

(b) X.H. BuJ, S. Johnson, X.H. BuD, A. Evans, Acc. Chem. Res. 33 (2000) 325;

(c) P. Kanoo, R. Matsuda, M. Higuchi, S. Kitagawa, T.K. Maji, Chem. Mater. 21 (2009) 5860.

[2] (a) W. Yang, X. Lin, A.J. Blake, C. Wilson, P. Hubberstey, N.R. Champness, M. Schröder, Inorg. Chem. 48 (2009) 11067;

(b) Y. Yan, S. Yang, A.J. Blake, M. Schrőder, Acc. Chem. Res. 47 (2014) 296.

[3] (a) Y. Li, R.T. Yang, Langmuir 23 (2007) 12937; (b) J.A. Greathouse, M.D. Allendorf, J. Am. Chem. Soc. 128 (2006) 10678.

[4] J. Sheikh, H. Juneja, V. Ingle, P. Ali, T.B. Hadda, J. Saudi Chem. Soc. 17 (2013) 269.

[5] Y. Harinath, D.H.K. Reddy, B.N. Kumar, C. Apparao, K. Seshaiah, Spectrochim. Acta A Mol. Biom. 101 (2013) 264.

[6] A. Chakraborty, P. Kumar, K. Ghosh, P. Roy, Eur. J. Pharmacol. 647 (2010) 1.

[7] C. Marzano, M. Pellei, F. Tisato, C. Santini, Anticancer Agents Med. Chem. 9 (2009) 185.

[8] S.G. Baca, S.T. Malinovskii, P. Franz, C. Ambrus, H. Stoeckli-Evans, N. Gerbeleu, S. Decurtins, J. Solid State Chem. 177 (2004) 2841.

[9] S.G. Baca, I.G. Filippova, O.A. Gherco, M. Gdaniec, Y.A. Simonov, N.V. Gerbeleu, P. Franz, R. Basler, S. Decurtins, Inorg. Chim. Acta 357 (2004) 3419.

[10] S. Wang, Y. Hou, E. Wang, Y. Li, L. Xu, J. Peng, S. Liu, C. Hu, New J. Chem. 27 (2003) 1144.

[11] (a) Đ.R. Stojaković, D. Poleti, R. Aleksić, J. Serb. Chem. Soc. 50 (1985) 241; (e) D. Poleti, ð. Stojaković, Thermochim. Acta 205 (1992) 225. (f) D. Poleti, Lj. Karanović, J. Serb. Chem. Soc 62 (1997) 657.

[12] M. Biagini-Cingi, A.M. Manotti-Lanfredi, A. Tiripicchio, M. Tiripicchio-Camellini, Acta Crystallogr. 34 (1978) 412.

[13] M.B. Cingi, A.M. Manotti-Lanfredi, A. Tiripicchio, M. Tiripicchio-Camellini, Acta
Crystallogr. 833 (1977) 659.

[14] J. Zdravković, D. Poleti, J. Rogan, D.M. Minić, Polyhedron 80 (2014) 256.

[15] A.M. Kirillov, Y.Y. Karabach, M.V. Kirillova, M. Haukka, A.J.L. Pombeiro, Cryst. Growth Des. 12 (2012) 1069.

[16] Z.G. Gu, S.C. Sevovti, J. Mater. Chem. 19 (2009) 8442.

[17] Y.Y. Karabach, A.M. Kirillov, M.F.C. Guedes da Silva, M.N. Kopylovich, A.J.L. Pombeiro, Cryst. Growth Des. 6 (2006) 2200.

[18] J. Rogan, D. Poleti, Thermochim. Acta 413 (2004) 227.

[19] J. Goldsmith, A.G. Wong-Foy, M.J. Cafarella, D.J. Siegel, Chem. Mater. 25 (2013) 3373.

[20] (a) G. Férey, Chem. Soc. Rev. 37 (2008) 191.

[21] J.R. Li, R.J. Kuppler, H.C. Zhou, Chem. Soc. Rev. 38 (2009) 1477.

[22] D. Poleti, B. Prelesnik, Đ. Stojaković, R. Herak, J. Serb. Chem. Soc. 50 (1985) 389.

[23] (a) W. Brzyska, W. Wotodkiewicz, J. Therm. Anal. 34 (1988) 1207;

(b) H. Langfelderova, J. Therm. Anal. 41 (1994) 955;

(c) A.K. Galwey, Thermochim. Acta 355 (2000) 181.

[24] (a) J.D. Gale, Philos. Mag. B 73 (1996) 3;

(b) J.D. Gale, J. Phys. Chem. B 102 (1998) 5423

[25] A. Gupta, S. Chempath, M.J. Sanborn, L.A. Clark, R.Q. Snurr, Mol. Simulat. 29 (2003) 29.

[26] A.K. Rappe, C.J. Casewit, K.S. Colwell, W.A. Goddard III, W.M. Skiff, J. Am. Chem. Soc. 114 (1992) 10024.

[27] F.M. Richards, Annu. Rev. Biophys. Bioeng. 6 (1977) 151.

[28] (a) M.J. McGinn, B.R. Wheeler, A.K. Galwey, Trans. Faraday Soc. 67 (1971) 1480; (c) J. Zdravković, D. Poleti, J. Rogan, N.N. Begović, V.A. Blagojević, M. Vasić, D.M. Minić, J. Therm. Anal 123 (2016) 1715.

[29] J.F. Arenas, J.I. Marcos, Spectrochim. Acta A 36 (1980) 1075.

[30] J.F. Arenas, J.I. Marcos, Spectrochim. Acta A 35 (1979) 355.

[31] G.B. Deacon, R.J. Phillips, Coord. Chem. Rev. 33 (1980) 227.

[32] S.K. Chawla, M. Arora, K. Nattinen, K. Rissanen, J.V. Yakhmi, Mendeleev Commun. 16 (2006) 20.

[33] Y. Cheng, A. Kondo, H. Noguchi, H. Kajiro, K. Urita, T. Ohba, K. Kaneko, H. Kanoh, Langmuir 25 (2009) 4510.

[34] G. Beobide, O. Castillo, A. Luque, U. Garcia-Couceiro, J.P. Garcia-Teran, P. Roman, Inorg. Chim. Acta 359 (2006) 2583.

[35] H.E. Kissinger, Anal. Chem. 29 (1957) 1702.

[36] T.J. Ozawa, J. Therm. Anal. 2 (1970) 301.

[37] T. Ahakira, T. Sunose, Res. Rep. Chiba Inst. Technol. Sci. Technol. 16 (1971) 22.

[38] A. Ortega, Thermochim. Acta 474 (2008) 81.

[39] (a) S. Vyazovkin, A.K. Burnham, J.M. Criado, L.A. Pérez-Maqueda, C. Popescu, N. Sbirrazzuoli, Thermochim. Acta 520 (2011) 1;

(b) S. Vyazovkin, K. Chrissafis, M.L. Di Lorenzo, N. Koga, M. Pijolat, B. Roduit, N. Sbirrazzuoli, J.J. Suñol, Thermochim. Acta 590 (2014) 1.

[40] S. Vyazovkin, C.A. Wight, Int. Rev. Phys. Chem. 17 (1988) 407.

[41] S.V. Vyazovkin, A.I. Lesnikovich, Thermochim. Acta 165 (1990) 273.

[42] A. Perejón, P.E. Sanchez-Jimenez, J.M. Criado, L.A. Pérez-Maqueda, J. Phys. Chem. B 115 (2011) 1780 .

[43] (a) J. Màlek, Thermochim. Acta 200 (1992) 257; (b) J. Màlek, Thermochim. Acta 138 (1989) 337.

[44] J. Šesták, G. Berggren, Thermochim. Acta 3 (1971) 1.

[45] F. Gotor, M.J. Criado, J. Màlek, N. Koga, J. Phys. Chem. A 104 (2000) 10777.

[46] A.L. Pérez-Maqueda, M.J. Criado, J.F. Gotor, J. Màlek, J. Phys. Chem. A 106 (2002) 2862.

[47] (a) K. Sillar, A. Hofmann, J. Sauer, J. Am. Chem. Soc. 131 (2009) 4143; (b) R.B. Rankin, J. Liu, A.D. Kulkarni, J.K. Johnson, J. Phys. Chem. C 113 (2009) 16906;

(c) J. Liu, R.B. Rankin, J.K. Johnson, Mol. Simulat. 35 (2009) 60;

(d) R. Babarao, J. Jiang, J. Am. Chem. Soc. 131 (2009) 11417;

(e) R. Babarao, J. Jiang, S.I. Sandler, Langmuir 25 (2009) 5239.

[48] C.R. Groom, F.H. Allen, Angew. Chem. Int. Ed. 53 (2014) 662.

[49] (a) S.S. Han, H. Furukawa, O.M. Yaghi, W.A. Goddard, J. Am. Chem. Soc. 130 (2008) 11580;

(b) S.S. Han, W.Q. Deng, W.A. Goddard, Angew. Chem. Int. Ed. 46 (2007) 6289; (c) S.S. Han, W.A. Goddard, J. Am. Chem. Soc. 129 (2007) 8422.

[50] S. Chavan, J.G. Vitillo, D. Gianolio, O. Zavorotynska, B. Civalleri, S. Jakobsen, M.H. Nilsen, L. Valenzano, C. Lamberti, K.P. Lillerud, S. Bordiga, Phys. Chem. Chem. Phys. 14 (2012) 1614. 